\title{
Centres of Attention in (Literary) Translation
}

\author{
Kirsten Malmkjær \\ University of Leicester, UK \\ km240@le.ac.uk
}

Received: May 28, 2020

Accepted: July 12, 2020

Published: October 26, 2020

\begin{abstract}
A fair deal of attention has been devoted in Translation Studies to translating for children, whereas little has been written about translating the writings of a child. Concomitantly, little attention has been devoted to how one might deal with the kinds of error in writing that a child might make in syntax and lexis. The work I discuss here was authored in English in by a nine-year-old female child in 1890 and translated into Danish in 1986 by a man in his early middle age, so there are several forms of temporal distance involved. However, the central issue to be faced by a translator of this work, I argue, is conveying the authorial style, which plays a considerable role in the work's appeal, and given that errors of spelling and expression are important elements of the authorial style in this work, the main challenge that it poses for a translator is to introduce similar phenomena into the translation in a credible manner, something that I argue, and hope to have illustrated, that he has achieved.
\end{abstract}

Keywords: literary translation, translation studies, children's writings, authorial style, writing errors

\section{Introduction}

In this article, I want to address a neglected issue in Translation Studies neglected in part, I suspect, because it is rare, namely the translation of the writings of a child. Whereas a fair deal of attention has been devoted to translating for children (see in particular Oittiinen and Puurtinen), none has so far been devoted to how one might approach a child's own writing. This activity raises an issue that has been of considerable interest in translation and interpreting studies (see e.g. Mikkelson, 2012; Mossop, 
1995), and also among practicing translators ${ }^{1}$, namely the issue of how to deal in interpreting and translating with source texts that are defective from the point of view of the syntax and lexis of the standard language: do we follow a "rubbish in - rubbish out" strategy, or do we improve on what we have been given to work with?

Interpreters, according to studies by e.g. Miguelez (2001) and Lee (2009), tend to correct speech errors, eliminate redundancy and repetition, and simplify questions, focusing on the main points of them, unless the speaker's message is so garbled that the interpreter is unable to work out what was probably meant (Mikkelson, 2012, p. 214). This tendency flies in the face of interpreters' code of ethics ${ }^{2}$, which states in "Canon 1. Accuracy" that

Source-language speech should be faithfully rendered into the target language by conserving all the elements of the original message while accommodating the syntactic and semantic patterns of the target language. The rendition should sound natural in the target language, and there should be no distortion of the original message through addition or omission, explanation or paraphrasing.

Mikkelson points to cases in which accuracy of rendering is particularly important. For example, if a child witness in a court case says "he showed me his pipi", this "should not be made more anatomically explicit by the interpreter, or the jury would have a distorted impression of the child's level of sophistication" (Mikkelson, 2012, p. 202). However, the child Mikkelson imagines or refers to here is not making an error; he or she is selecting one among a number of options (albeit not all of these may be available to the child) to refer to the body part in question. However, in most cases of a defective source text, the tendency is for translators to correct, and guidance is even available on how to spot source text errors and deal with them -- see e.g. Mossop (1995), who offers advice on numerous kinds of textual unhappiness including physical production errors (1995, Section 4), which, I assume, would include spelling and grammatical errors. Unsurprisingly, then, little is written in the translation studies literature about the replication of grammatical and spelling errors in source texts.

\footnotetext{
${ }^{1}$ See e.g.http://bit.ly/2XoS7YW Retrieved September 14, 2020.

${ }^{2}$ See https://bit.ly/38tKwPi Retrieved September 14, 2020.
} 
In the work I discuss here, errors of spelling and certain modes of expression are important for reasons relating to (literary) authorial style and voice and the relationship they establish between author and reader. I will begin with a discussion of affect and its relationship to text. Next, I will discuss the relationships between translators and affect, and finally, I will introduce a case that illustrates one translator's strategies for maintaining the eccentricities that characterize one particular literary work, contributing significantly to its affective potential.

\section{Affect}

Buswell (1935) made photographic records of the eye movements made when looking at various types and shapes of art work by sixty one subjects who had studied art in The Arts School of the Art Institute of Chicago, or in similar institutions, and by subjects who had had no training in art (there was also a group of primary school children involved in the experiment). He identified what he calls "centres of attention" (p. 18), being careful to stress that it is not possible to infer from where a centre of attention is, whether or not the viewer approves of what he or she is seeing there; it is not possible to draw a link to the specific, individual emotions of the viewer (p. 10). Nevertheless, we might guess that a centre of attention is also a potential centre of affect (whatever the precise affect might be).

Affect is defined by the American Psychological Association (APA) Dictionary of Psychology (online) as follows:

$\mathrm{n}$. any experience of feeling or emotion, ranging from suffering to elation, from the simplest to the most complex sensations of feeling, and from the most normal to the most pathological emotional reactions. Often described in terms of positive affect or negative affect, both mood and emotion are considered affective states. Along with cognition and conation, affect is one of the three traditionally identified components of the mind.

Cognition is the experience of knowing and understanding, and conation is the experience of willing or desiring. Emotions and moods that are experienced (and constitute affect) are states of mind - mental states like sadness, joy, excitement, boredom and so on.

Hubscher-Davidson (2018, p. 2) identifies "three distinctive areas where emotions influence translators: emotional material contained in source 
texts, their own emotions, and the emotions of source and target readers". The notion of "emotional material contained in the source text", Hubscher-Davidson's first area of potential influence on translators, may seem problematic. According to Rikhardsdottir (2017, p. 6), it is unclear "how we can transpose a term that refers to the physiological and neurological activity of an organism to discursive constructions that do not possess such interiority or such physicality". But while it is true that a formulation like Hubscher-Davidson's "emotional material in the source text", which probably reflects fairly common usage, may be misleading (of course, the material is not emotional in the sense that a person may be emotional), it is widely accepted in psychology that texts may imitate or represent life and that, for example, "a play or novel allows us to compare an explicitly simulated set of actions and their results with emotions that are our own and that may move us considerably" (Oatley, 1992, p. 126).

Hubscher-Davidson (2016, p. 133) points out that many of the text types that translators deal with "may elicit strong emotional responses (e.g., rape depositions)"; and Rikhardsdottir (2017, p. 4) herself remarks that "Skaldic [Viking age] poetry displays heavily ornamented rhetoric that often originates in profound emotions or is intended to convey (or elicit) such emotions".

In the context of art, such views represent what is known as "expression theories of art"; the artist is thought to feel "an emotion that he or she transmits to the audience by way of the work" (Matravers, 2005, p. 445). So if we consider a translation a work of art, we might suggest that the translator feels an emotion engendered by the work to be translated, which he or she seeks to transmit to the reader of the translation by way of the translation. As well as being an expression theory, this is also an arousal theory insofar as the claim is that the source text gives rise to an emotion in the translator. This cannot be assumed to hold for all cases of translation, because it is quite possible for a translator to feel no affect resulting from the work he or she is translating, just as, after all, "Many celebrated artists have expressly denied that emotion lay at the heart of their endeavours" (Graham, 2005, p. 136). 
The essence of an arousal/expression theory of translation would of course not be novel within translation theory; Nida (1964) writes at length about the concept of similar effect, and the central difficulty with the approach is well established: how can it be decided whether the effect is the same in the two (three, including the translator) perceivers: the perceiver of the source text and the perceiver of the translation? The existence of multiple translations of the same source text strongly suggests that not every translator makes the same assumptions as every other translator about what would create the same effect (if that is even what a translator is trying to do), or, it indicates that the translators were affected differently by the source text, which may be why their translations differ. One way of identifying potential centres of attention in translating might be to focus on areas of text where translators' choices differ; these areas of the source text may be more demanding of attention than areas where the translations do not differ, either because the source text is challenging or especially poignant in these areas, or because it is difficult to convey in the language of the translation whatever was conveyed at these points in the source text, for linguistic or cultural reasons, or both. This method of identifying centres of attention would obviously only work in cases where there are multiple translations of the same text. Another obvious method is to read translators' accounts of the translating process and of their concerns during it. Both these possibilities tend to be available for literary translation almost exclusively, at least when long stretches of text are in focus, because it is literary texts that tend to have multiple translations.

Here, I am combining reference to a translator's declared focus of attention with textual analysis of his translation of a literary text.

To return to the idea that a translator might experience an emotion upon reading a source text and that he or she would like to engender the same emotion in readers of his or her translation: translators themselves testify to this. As Boase-Beier and de Vooght (2019, p. 17) put it,

Translation ... is never about getting it right, about approximating the form or content of the original, about making a copy for those who do not speak Yiddish, or Latvian or French. It is about recognising someone else's story, 
understanding the way the teller has chosen to tell it, and passing it on to others.

In the case of the translations collected in Boase-Beier and de Vooght's Poetry of the Holocaust: An Anthology, we know that affect lay at the heart of the work of both the poets and the translators. In their preface, Boase-Beier and de Vooght (2019, p. 18) remark that "all the poems collected here are written from the heart, and each poem was chosen because it gives us the opportunity to think about how people were affected by the events they witnessed or are reflecting on". One would like to think that the kinds of emotion that such a collection, or parts of such a collection, may arouse are more than purely a social construct that they are at least admixed with or influenced by some emotions that are biologically endowed, "an innate system of basic emotions" as Bucciarelli and Johnson-Laird (2019, p. 89) posit (see also Oatley \& Jenkins, 1996, pp. 49-50). These emotions "have their own distinctive signals in the brain and in universal facial expressions", paradigm examples being happiness, sadness, anger, anxiety and disgust, and they are often experienced as bound up with a propositional content; this connection to content makes them complex (Bucciarelli \& JohnsonLaird, 2019, pp. 100-101). Complex emotions include remorse, jealousy and pride: "Remorse, for instance, is sadness about an action or inaction that harms another, and individuals have this emotion because they judge themselves to have violated the moral code embodied in their idealized models of themselves" (p. 101). "Emotions often produce empathy in others and they can create and maintain relationships such as happy cooperation or angry conflict" (Oatley \& Johnson-Laird, 2014, p. 135). They have "different time courses, from a few seconds for facial expressions to minutes or hours for experiences of emotion ..., months for psychological illnesses, and lifetimes for emotion-based traits of personality" (p. 136). People who are unable to name their emotions or perhaps even experience emotions are said to have alexithymia, and some people experience emotional apathy, which is "lack of motivation not attributable to diminished level of consciousness, cognitive impairment or emotional distress" (Marin, 1991, 1996). This "may be characterised by emotional blunting" (Ang et. al, 2017, Discussion), also known as 
"reduced affect display", and it can be considered psychologically pathological (Kashdan et. al, 2007), again reinforcing the notion that the ability to empathise and feel affect is normal for humans.

Of course, for human emotions to have an effect on the world, it is necessary for cognition and conation to interact with emotions. As Oatley and Johnson-Laird (2014, p. 137) put it, "cognitive reflection on the meaning of an emotion... can lead to new intentions". "Emotions", according to Zhu \& Thagard (2002, p. 20)

are evaluative and responsive patterns that emerge through the evolution of the species and the development of individuals. They serve the function of providing appraisals about whether what is happening is harmful, threatening, or beneficial to our well-being under certain conditions.

Such primary appraisal is typically followed by secondary appraisal which "focuses on possible ways of coping with the situation" (p. 27).

\section{Affect and Translators}

Hubscher-Davidson (2018, p. 14) believes "that there are certain stable personality traits and behavioural dispositions that are helpful for translation". She charts work in translation studies that has focused on affect (2018, pp. 27-37) and presents the results of a questionnaire study intended "to shed light on the role of emotions in translation, and, especially, how emotions influence professional translators" (2018, p. 37). She investigates 155 professional translators, 122 women and 33 men, with a mean age of 47 years (the age range was 21 to 87 years). She finds that emotion perception in translators is positively associated with age (2018, p. 91), with experience of literary translation, with professional translation experience (2018, pp. 91 and 96), and with job satisfaction $(2018$, p. 96). Interestingly, there was no link to translators' familiarity with foreign cultures. The ability of translators to regulate their emotions was positively associated with professional translation experience (2018, p. 129), with level of education (2018, p. 131), with how much of a person's work time is spent on translation work (2018, p. $133)$, with job satisfaction and success (2018, p. 134) and with literary translation experience $(2018$, p. 137). There was no link to having a translation qualification (2018, p. 131). Translators' ability to express their emotions correlated positively with years of professional translation 
experience and with literary translation experience (2018, pp. 178 and 184), job satisfaction and success (2018, p. 180), and education level (2018, p. 181). There was no correlation between emotion expression and either translation qualifications or time spent translating (2018, pp. 181 and 184). She concludes that

the profile of a highly emotionally competent translator might be someone older/mature, educated to degree level, with several years of professional translation experience, who is satisfied with his or her job, and who has some experience of undertaking literary translation. Emotionally competent translators are also likely to be undertaking other professional activities alongside translation, therefore not spending the majority of their time translating. (p. 195)

\section{The Focal Text and its Translation}

The translation I will focus on here is very far removed from the work in Boase-Beier and de Vooght's (2019, p. 18) anthology. It is a translation into Danish of The Young Visiters or Mr Salteena's Plan, written by Daisy (Margaret Mary Julia) Ashford (1881-1972) in 1890, when she was nine years old, and first published in 1919 in London by Chatto and Windus/The Hogarth Press. Its Danish title is De unge elskene eller $\mathrm{Mr}$ Salteenas plan (The young lovers or Mr Salteena's plan), and it was published in 1986 by Nyt Nordisk Forlag Arnold Busk A/S. The translator, Poul Malmkjær, has translated regularly since he was 20, and was, at the time of translating this work, in his early 50s, having had, therefore, around 30 years' experience of making translations.

Translating is by no means the only occupation he has enjoyed, having been a sailor, soldier, film historian, editor of Denmark's oldest film journal, Kosmorama, ${ }^{3}$ and employed as a film expert and presenter of film programmes at Radio/TV Denmark for 31 years. He has also had minor film roles. He says of De unge elskene, that it was "a labour of love" (personal communication), so all in all he fits Hubscher-Davidson's profile of the highly emotionally competent translator exceptionally well. His emotional engagement with the work is made clear in the Translator's Notes (p. 7; my translation):

One of life's plentiful pleasures is the completion of a piece of enjoyable work. In the case of the translation of Daisy Ashford's novel, however, my joy was

\footnotetext{
${ }^{3}$ See https://bit.ly/3ntUYdX Retrieved September 14, 2020.
} 
admixed with grief that the book wasn't longer, that it ended, that my work was not to continue.

The Young Visiters is unusual in that the narrating voice is that of a nineyear old female child who is in fact the author; so the voice is not that of an adult writing as a child, as in the case of Jacqueline Wilson's The Story of Tracy Beaker (1991), for example. The Young Visiters is written by a real child. The narration is in the third person, and the narrator selfrefers at the ends of some chapters, including her readership in some of these self-references, e.g. at the end of Chapter Two: "Here we will leave our friends to unpack and end this chapter". Clearly, the author is well versed in literary conventions; she was apparently encouraged to write as a child ${ }^{4}$, and J. M. Barrie's preface to The Young Visiters explains that as a child, Daisy Ashford "read everything that came her way, including, as the context amply proves, the grown-up novels of the period" (Barrie 1919/1984, p. 8).

The translator, in contrast, is an adult male. He says of his experience of translating The Young Visiters (Translator's Remarks, p. 7; my translation):

The main difficulty with the translation was the zeitgeist. I have made no attempt to use the Danish of the [18]90s as it might be (mis)understood by a girl of nine. I have used concrete expressions from the time when describing clothes and objects (for example 'toque' or 'top boots' ['kravestøvler']), but in descriptive passages and dialogue I have moved the language towards our own time as gently as I could.

The spirit of the time, then, was a centre of attention for him; and it is interesting to note that this is a rather wide centre of attention (if centres can be wide), and not one that could easily be identified by way of eyetracking, for example.

In the quotation above, the translator also mentions the author's age. Rosenwein (2006, p. 2) uses the term "emotional communities" to refer to "groups in which people adhere to the same norms of emotional expression and value - or devalue - the same or related emotions" (see Rikhardsdottir, 2017, p. 25). Arguably, a nine-year old child and an adult belong to somewhat different emotional communities; as Oatley (1992, p.

\footnotetext{
${ }^{4}$ See her biography at http://imdb.to/2XqaLQ1 Retrieved September 14, 2020.
} 
10) points out

life changes in its emotional patterns from infancy to adulthood. Emotions in childhood seem more salient, more intense, more frequent than in adulthood. There are clear continuities, but there is also the question of whether adult emotions concern different matters than those of childhood.

The Young Visiters reports the kinds of event that typically arouse strong emotions in adults; it is a love story (of sorts) focusing on a young woman, Ethel, and two suitors of whom she chooses one (Bernard) to the distress of the other (Mr Salteena). The narrator clearly understands the emotions involved on an intellectual level, but, being a child, does not have full access to the gamut of adult feelings such events generally release. She therefore confines herself to describing the visible signs of such emotions; for example, on p. 26, in a scene in which Ethel first encounters Bernard (Ashford 1919/1984, p. 26):

Oh yes gasped Ethel blushing through her red ruuge.

Bernard looked at her keenly and turned a dark red.

When she describes affect, it is in passages that deal with emotions that a child may feel. For example, "Ethel was calm but she felt excited inside" on the way, by train, to visit Bernard (Ashford 1919/1984 edition, p. 24).

A child's perspective is evident in many scenes and in many aspects of the narration. For example, here is Mr Salteena being helped (by the butler Procurio) to get ready for a party to be hosted by the Prince of Wales (Ashford 1919/1984, p. 47):

Then they rummaged among Mr Salteenas things and Procurio got very intelligent and advised Mr Salteena to wear his black evening suit and roll up his trousers. He also lent him a pair of white stockings which he fastened tightly round his knees with red rosettes. Then he quickly cut out a star in silver paper and pinned it to his chest and also added a strip of red ribbon across his shirt front.

Or consider "Oh Hurrah shouted Ethel I shall soon be ready as I had my bath last night so wont wash very much now" (Ashford 1919/1984 edition, p. 65).

However, such passages cause the translator no apparent specific difficulties. Rather, he mentions spelling as a further centre of his attention - again one that stretches across the whole work. He explains (pp. 7-8; my translation) 
Daisy Ashford was very good at spelling, but she was only nine years old, and it is quite understandable that her text exhibits a selection of errors - odd, in the case of simple words, understandable when she takes on difficult, adult words. She consistently misspells the word "idea". In contrast, it is unlikely that a child would misspell the Danish word "ide". It is an easy word. In such cases, I have tried to find a different word in the sentence which a nine-year old Dane would have stumbled over.

For example, in the first sentence of the story, Mr Salteena is said to be "fond of asking peaple to stay with him" (Ashford 1919/1984 edition, p. 19). The translator postpones an error until the second sentence, selecting the Danish word for 'quite' (in the sense of 'rather'), temmelig, which is often pronounced 'temlig', and spells it accordingly (Ashford/P. Malmkjær 1986, p. 19).

You might think that a strategy of representing spelling errors gives a translator considerable freedom; however, for the strategy to work, and to maintain affect, the misspelling has to be logical and consistent, and it is this feature of the translation that I want to focus on.

The misspellings are important because this aspect of the author's output contributes to the appeal of the book -- its potential for affect. They are singled out as doing so both by J. M. Barrie in his preface to the original and by the translator in his remarks. For errors of spelling to have the same effect in the translation, they must be believable. The translator ensures this credibility in part by exploiting those aspects of the Danish spelling system where pronunciation is either an imprecise or a misleading guide to spelling. In particular, within words, the same consonantal sounds can be represented by either $\mathrm{gg} / \mathrm{g}$ or $\mathrm{kk} / \mathrm{k}[\mathrm{g}]$, or by either $\mathrm{dd} / \mathrm{d}$ or $\mathrm{tt} / \mathrm{t}[\mathrm{d}]$, or by either $\mathrm{pp} / \mathrm{p}$ or $\mathrm{bb} / \mathrm{b}$, [b]. Some vowel sounds can be represented by different letters, e.g. æ and e [œ] and some letters are redundant for pronunciation purposes, as in so many languages (including English), especially at the ends of syllables in the case of Danish. In the first two chapters, the following spelling errors occur in each version. I have not provided the correct spelling for the English words, though I have for the Danish to illustrate the strategies the translator has used. Bold is used where the meanings of the English and Danish words coincide. Numbers after the example indicate the pages where the example occurs. 


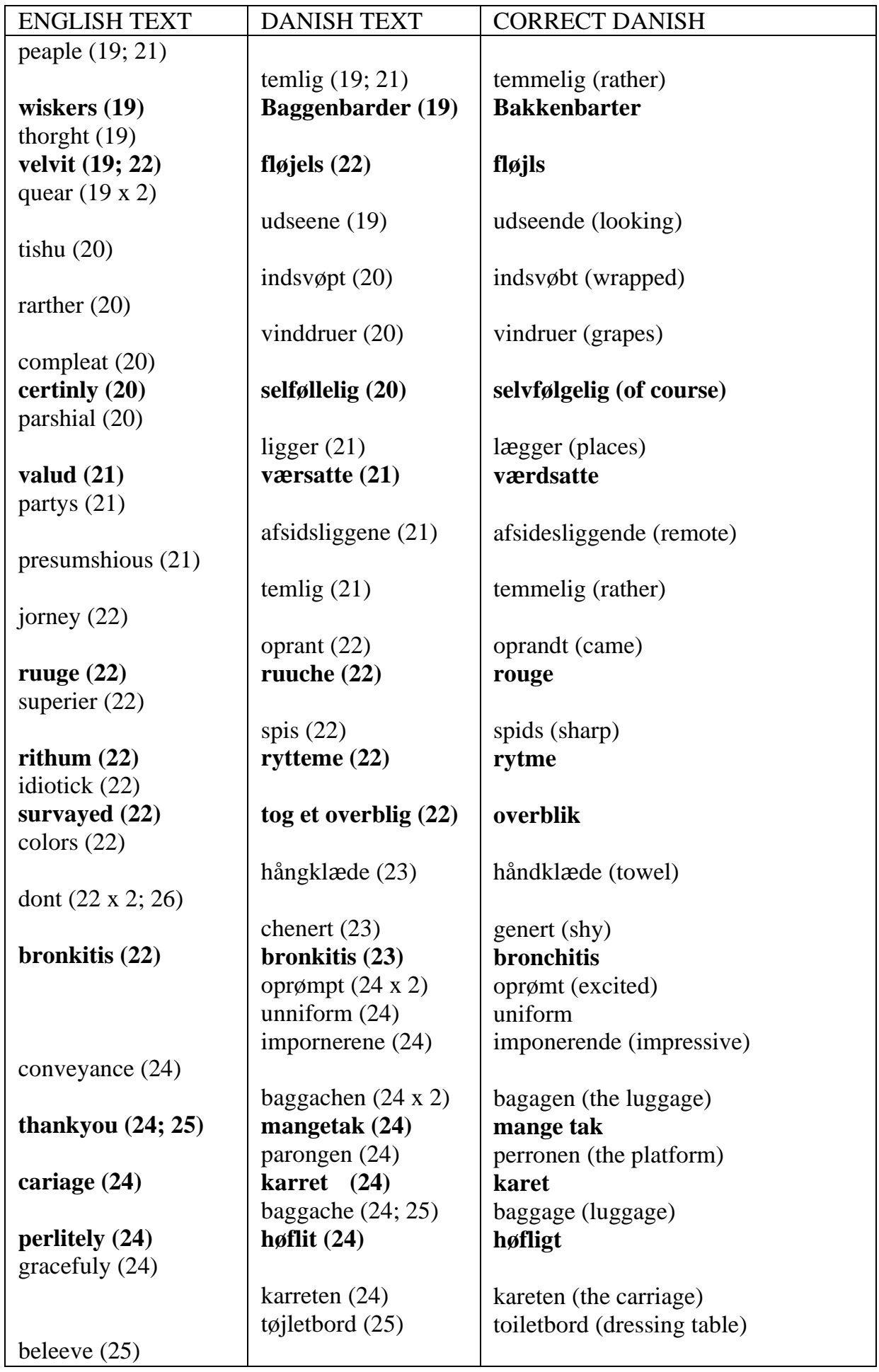




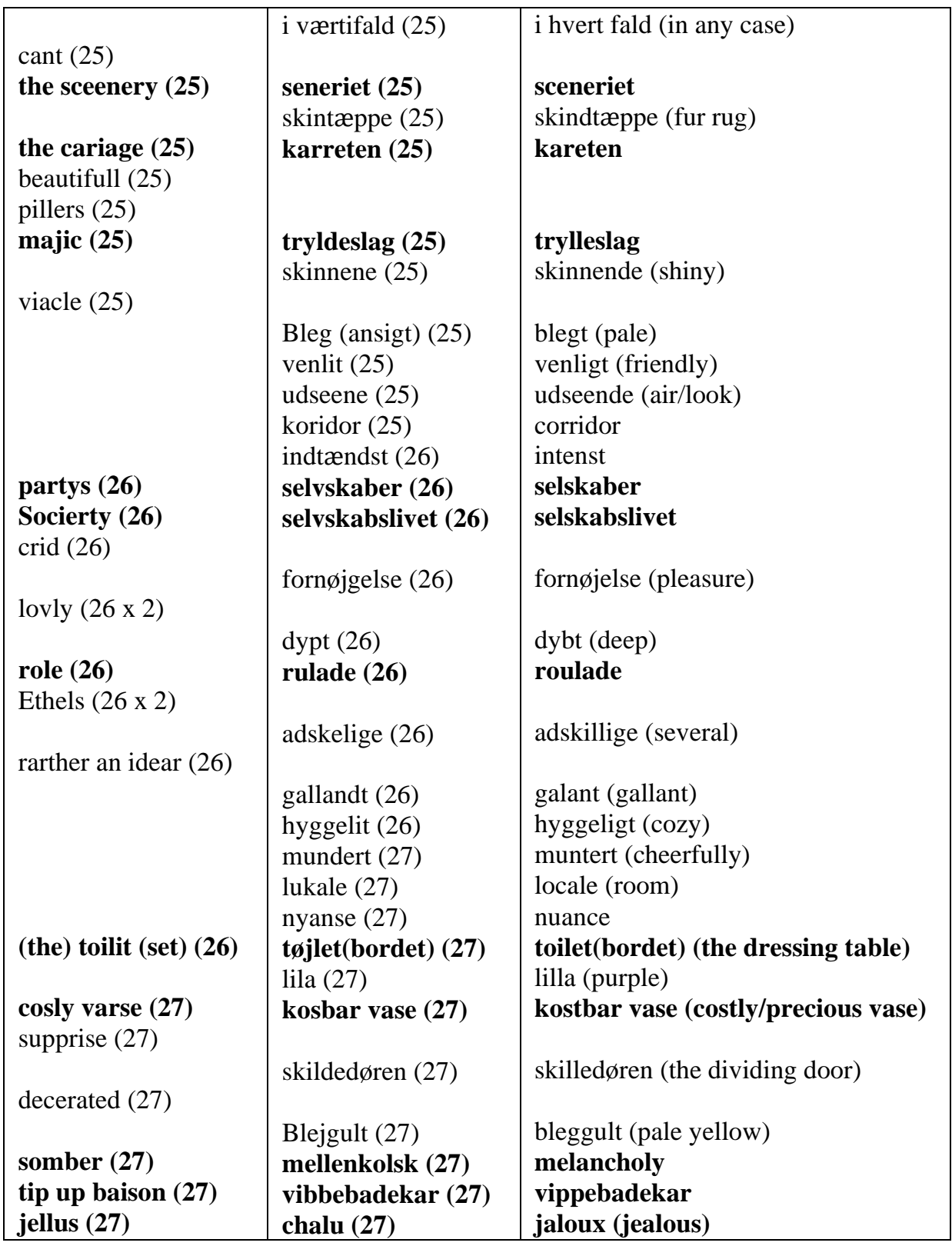

In the first two chapters of the book, there are marginally more spelling errors in the translation than in the source text, because the spelling convention-related strategy for error representation in the translation is applied fairly consistently, as it has to be, to be credible. There is also the typical child phrase, 'i værtifald' instead of 'i hvert fald', which means 
more or less 'in any case' in the sense of 'at least'. In some cases, the translator has inserting a joke, as in the translation of 'a huge pale face' (p. 25) as 'et stort bleg ansigt' (p. 25), which, because of the lack of a ' $t$ ' after 'bleg' suggests 'a large pale-face' in the sense that this term might occur in cowboy/Indian stories.

By using a largely pronunciation-guided strategy, the translator ensures credibility of the errors in the target text and sustains the aspect of the story's affective potential provided by the spelling. Any story is sustained not only by the events that are narrated in it, but also the manner in which they are narrated (Genette, 1972); similarly, character depiction depends not only on what is expressed, but also on how it is expressed. In the case in focus here, spelling, and its role in creating potential for affect, are important aspect of the narrative. The translator's consistent and logical representation of this feature ensures that it enriches the translation as much as it enriches the original story.

The case also illustrates that centres of attention can be conceptual rather than tied directly to textual matter - although textual matters are clearly affected by them and reflect them.

\section{References}

American Psychological Association (APA) Dictionary of Psychology. Retrieved March 15, 2020 from https://dictionary.apa.org/affect.

Ang, Y., Lockwood, P., Apps, M., Muhammed, K., \& Husain, M. (2017). Distinct subtypes of apathy revealed by the apathy motivation index. PLOS ONE 12(1): e0169938. https://doi.org/10.1371/journal.pone.0169938

Ashford, D. (1919/1984). The young visiters or Mr Salteena's plan. London: Chatto and Windus.

Ashford, D. (1919/1986). De unge elskene eller Mr Salteenas plan. Translated by Poul Malmkjær from The young visiters or Mr Salteena's plan. Copenhagen: Nyt Nordisk Forlag Arnold Busck A/S.

Barrie, J. M. (1919/1984). Preface. In Ashford, D., The young visiters or Mr Salteena's plan (pp. 7-13). London: Chatto and Windus.

Boase-Beier, J. \& de Vooght, M. (Eds.). (2019). Poetry of the holocaust: An anthology. Todmorden: Arc Publications.

Bucciarelli, M. \& Johnson-Laird, P. (2019). Deontics, meaning, reasoning, and emotion. Materiali per una storia della cultura giuridica, XLIX(1): 89-112.

Buswell, G. (1935). How people look at pictures: A study of the psychology of perception in art. Chicago: The University of Chicago Press.

Genett, G. (1972). Discours du recit. Paris: Editions due Seuil. 
Graham, G. (2005). Expressivism. In B. Gaut and D. M. Lopes, (Eds.), The Routledge companion to aesthetics ( $2^{\text {nd }}$ ed., pp. 133-145). London: Routledge.

Hubscher-Davidson, S. (2016). Trait emotional intelligence and translation: A study of professional translators. Target, 28(1): 132-157.

Hubscher-Davidson, S. (2018). Translation and emotion: A psychological perspective. London: Routledge.

Kashdan, T., Elhai, J., \& Frueh, B. (2007). Anhedonia, emotional numbing, and symptom overreporting in male veterans with PTSD. Personality and Individual Differences, 43(4): 725-735.

Lee, J. (2009). Conflicting views on court interpreting examined through surveys of legal professionals and court interpreters. Interpreting, 11(1): 35-56.

Marin, R. (1991). Apathy: A neuropsychiatric syndrome. Journal of Neuropsychiatry and Clinical Neuroscience, 3(3): 243-254.

Marin, R. (1996). Apathy: Concept, syndrome, neural mechanisms, and treatment. Seminars in Clinical Neuropsychiatry, 1: 304-314.

Matravers, D. (2005). Art, expression and emotion. In B. Gaut and D. M. Lopes (Eds.), The Routledge companion to aesthetics $\left(2^{\text {nd }}\right.$ ed., pp. 445-455). London: Routledge.

Miguelez, C. (2001). Interpreting expert witness testimony: Challenges and strategies. In I. Mason (Ed.), Triadic exchanges: Studies in dialogue interpreting (pp. 319). Manchester: St. Jerome Publishing.

Mikkelson, H. (2012). Garbage in, garbage out: The court interpreter's lament. In C. Bidoli (Ed.), Interpreting across genres: Multiple research perspectives. Trieste, EUT Edizioni Università di Trieste.

Mossop, B. (1995). Understanding poorly written source texts. Terminology Update, 28(2): 4. https://cutt.ly/8hPexFU

Nida, E. (1964). Towards a science of translating: With special reference to principles and procedures involved in Bible translating. Leiden: E. J. Brill.

Oatley, K. (1992). Best laid schemes: The psychology of emotions. Cambridge: Cambridge University Press.

Oatley, K. \& Jenkins, J. (1996). Understanding emotions. Cambridge: Blackwell Publishers Inc.

Oatley, K. \& Johnson-Laird, P. (2014). Cognitive approaches to emotions. Trends in Cognitive Science, 18(3): 134-140.

Rikhardsdottir, S. (2017). Emotion in old Norse literature: Translations, voices, contexts. Cambridge: D. S. Brewer.

Rosenwein, B. (2006). Emotional communities in the early middles ages. Ithaca: Cornell University Press.

Zhu, J. \& Thagard, P. (2002). Emotion and action. Philosophical Psychology, 15(1): 1936. 